\title{
Bilangan Bulat dan Kekeliruan dalam Operasi Matematika
}

\author{
Zahedi* $^{*}$ \\ Program Studi Matematika, F. MIPA USU \\ yasmine_badai@yahoo.com
}

\begin{abstract}
The challenge of Mathematics education is to find and choose learning models that are easy to understand, arousing, challenging to get involved in and eventually make students understand easily. This paper intends to be a bridge in the process of teaching and learning of integers and mathematical fallacies that often occur in mathematical operations. Integers play an important role in the development of mathematical knowledge and the use of these numbers enables the current generation to build space satellites and investigate the structure of the universe. Integers often look very simple but are actually very difficult to solve. On the other hand, carelessness in completing mathematical operations often results to fallacies that can cause ridiculousness. This paper is trying to review these two problems in an easy and fun way.
\end{abstract}

Keywords: learning model; integers; mathematical fallacies; mathematics operation; bridge

\begin{abstract}
Abstrak
Tantangan pendidikan Matematika adalah mencari serta memilih model pembelajaran yang mudah dipahami, menggugah, menantang untuk terlibat dan pada akhirnya menjadikan peserta didik gampang memahaminya. Tulisan ini bermaksud untuk menjadi jembatan dalam proses belajar mengajar pada bilangan bulat dan kekeliruan matematis yang sering terjadi dalam melakukan operasi matematika. Bilangan bulat memegang peranan penting dalam perkembangan pengetahuan matematika dan penggunaan angkaangka ini memungkinkan generasi sekarang untuk membangun satelit ruang angkasa dan menyelidiki struktur alam semesta. Bilangan bulat sering kali terlihat sangat sederhana tetapi sesungguhnya sangat sulit untuk dipecahkan. Dari sisi lain, ketidakhati-hatian dalam penyelesaian operasi matematika seringkali menimbulkan kekeliruan yang dapat menimbulkan kekonyolan. Artikel ini mencoba mengulas kedua masalah ini dengan cara yang mudah dan menyenangkan.
\end{abstract}

Kata Kunci: model pembelajaran; bilangan bulat; kekeliruan matematis; operasi matematika; jembatan

\footnotetext{
*Correspondence:

Email: yasmine badai@yahoo.com
} 


\section{PENDAHULUAN}

Sumber utama pelajaran matematika adalah bilangan bulat dan sudah seharusnya setiap peserta didik yang belajar matematika menyukai subjek ini.

Obsesi seseorang terhadap bilangan bulat bisa jadi terdengar konyol bagi banyak dari orang, tetapi bilangan bulat adalah cara terbaik untuk melampaui ruang dan waktu. Merenungkan hubungan yang menakjubkan dan membentang imajinasi di antara angka-angka ini, serta kegunaan angka-angka ini memungkinkan kita untuk membangun satelit ruang angkasa dan menyelidiki struktur dari alam semesta. Boleh jadi, bilangan akan menjadi alat komunikasi pertama dengan makhluk ruang angkasa.

Dahulu, seperti misalnya orang Yunani, memiliki ketertarikan yang mendalam dengan angka. Mungkinkah dalam masa-masa sulit angka adalah satusatunya hal yang konstan dalam dunia yang selalu berubah? Bagi pengikut Pythagoras, jumlahnya nyata, tidak berubah, nyaman, abadi - lebih bisa diandalkan daripada sahabat, dan lebih tidak mengancam daripada Zeus.

Mengapa peduli bilangan bulat? Bilangan bulat yang masuk dalam subjek teori bilangan dipercayai dapat menimbulkan masalah. Menggunakan bilangan bulat, sederhana untuk dinyatakan tetapi sulit untuk dipecahkan. Beberapa masalah yang belum terpecahkan dari satu abad adalah masalah dalam teori bilangan. Leopold Kronecker (1823-1891), seorang ahli ilmu aljabar dan teori bilangan Jerman, pernah berkata, "Bilangan bulat berasal dari Tuhan dan yang lainnya buatan manusia". Implikasinya adalah bahwa sumber utama semua matematika adalah bilangan bulat. Sejak zaman Pythagoras, peran rasio bilangan bulat dalam skala musik telah dihargai secara luas.

Disisi lain, sering terdapat kekeliruan dalam penyelesaian masalah matematika. Beberapa kekeliruan ini kemudian menjadi cukup terkenal. Teori umum mengatakan bahwa suatu gagasan yang keliru sering dapat diekspos lebih meyakinkan dengan mengikutinya pada kesimpulan yang absurd daripada dengan hanya mencela kesalahan dan memulai lagi.

Beberapa masalah tentang angka dan kekeliruan matematika yang dipaparkan secara menyenangkan dalam makalah ini harusnya dapat membuat banyak orang jatuh cinta pada angka atau matematika. Makalah ini akan menghibur orang di semua tingkat kecanggihan matematika yang fokus pada kreativitas, penemuan, dan tantangan dengan sedikit manipulasi matematis.

\section{PEMBAHASAN}

\section{a. Di Kasino}

Tidak banyak orang yang memiliki keistimewaan ingatan yang luar biasa dalam hal menghapal, termasuk mengingat tentang kartu dalam suatu permainan. Dominic O’Brien, seorang pria Inggris dapat menghapal - hanya 
pada satu pengamatan -, urutan acak dari 40 set kartu yang terpisah (semuanya berjumlah $2.080 \mathrm{kartu}$ ) yang telah dikocok bersama, dengan hanya satu kesalahan! Tercatat, waktu tercepat untuk menghapal satu set kartu yang sudah dikocok adalah 42 detik.

Sekarang kita akan mencoba prestasi yang sama dari ketangkasan mental ini. Di atas meja terdapat setumpuk kartu (gambar 1).

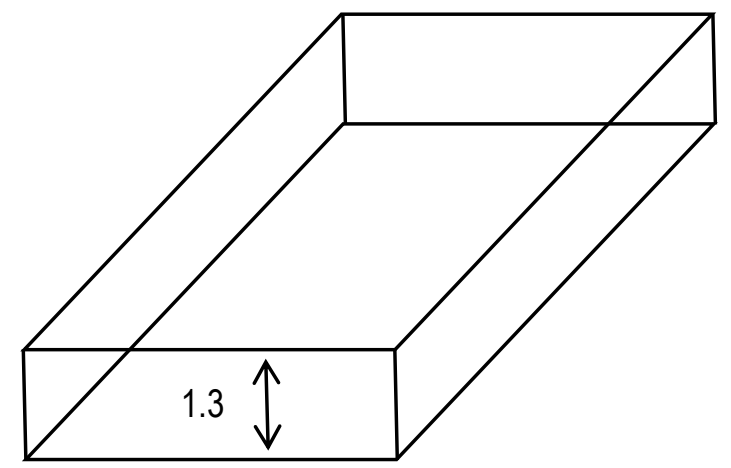

Gambar 1. Setumpuk Kartu

Sekarang, kita tidak akan menghitung banyak kartu tetapi akan menguji kemampuan lain. Jika dilihat dari samping, satu set kartu berukuran tinggi 1.3 sentimeter, berapa ukuran atau tingginya jika semua Raja diambil?".

Penyelesaian: Jumlah kartu dalam 1 set adalah 52. Terdapat ada 4 set kartu, dan masing-masing dikeluarkan 1 kartu maka ada 4 kartu yang dikeluarkan. Artinya pengukuran berkurang pada 1/13. Selanjutnya operasi matematika yang dilakukan adalah mengurangi 0.1 dari 1.3. Jadi jawabannya atau ukuran atau tinggi kartu sekarang adalah $1.2 \mathrm{~cm}$.

Pekerjaan selanjutnya adalah membuat masalah yang lebih sulit, jika setumpuk kartu tanpa King tebalnya $1.2 \mathrm{~cm}$. Berapa tebal tumpukan kartu jika kita mengambil 4 King dan menambahkannya ke tumpukan kartu?. Masih belum cukup sulit? Seberapa tebal tumpukan kartu jika Queens diambil dari semua kartu lain yang menunjukkan bilangan prima? Selanjutnya, berapa banyak angka pi $(3.1415$...) yang dapat ditampilkan dengan setumpuk kartu?

\section{b. Siklus Segitiga}

Mari kita lihat masalah yang disebut Siklus Segitiga (Triangle Cycle) berikut. Masalah dimulai dengan bentuk geometri yang sederhana — segitiga - dan segera menjadi sangat rumit. Tempatkan satu digit di setiap sudut segitiga sehingga garis-garis yang menghubungkan angka-angka yang berdekatan membuat angka 2 digit yang merupakan kelipatan dari 7 atau 13 (angka 2 digit harus merupakan kelipatan hanya dalam 1 arah). Misalnya, 
garis yang menghubungkan 1 dan 9 adalah valid karena kita dapat membacanya sebagai 19 atau 91, dan 91 sama dengan 13x7. Kita dapat membuat segitiga yang dimulai dengan dua digit ini dengan meletakkan angka 3 di sudut ketiga, seperti yang terlihat pada Gambar 2a. Salah satu dari garis-garis ini menghubungkan 1 dan 3, membentuk angka 13 (13 kali 1), sedangkan yang lain menghubungkan 3 dan 9, membentuk 39 (13 kali 3). Tapi masalah ini masih jauh dari selesai.

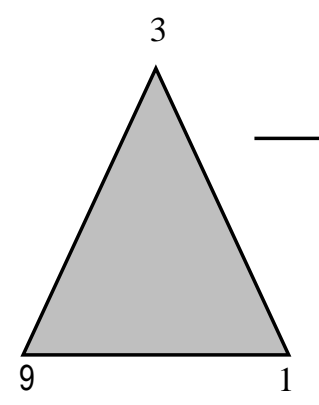

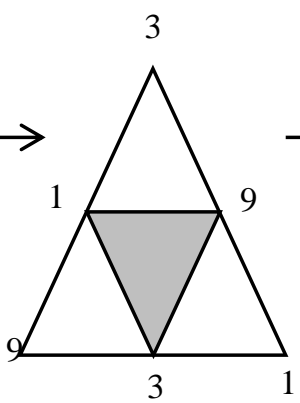

b

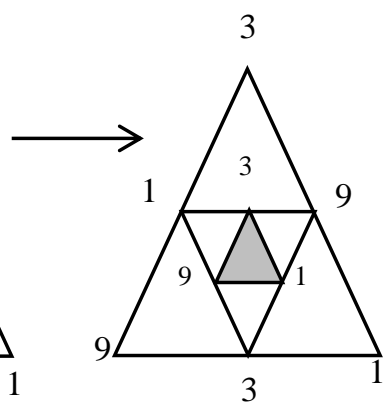

c

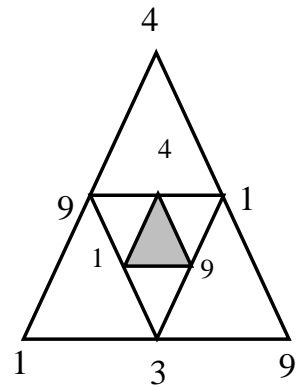

d

Gambar 2. Papan Bermain untuk Permainan Siklus Segitiga

a. Posisi Awal

b. Segitiga di dalam Segitiga

c. Siklus 1 Penyelesaian

d. Siklus 2 Penyelesaian

Penyelesaian: Gambarlah segitiga baru di dalam segitiga pertama, dengan sudut-sudutnya memotong sisi-sisi segitiga yang lebih besar menjadi dua. Sekarang pilih 3 angka lagi untuk sudut-sudut baru. Hati-hati: Kita sebenarnya telah membuat 4 segitiga, dan masing-masing harus mematuhi aturan yang diuraikan di atas. Solusi termudah menggunakan 3 angka yang sama (lihat Gambar 2.b). Pertama lihat 6 garis yang membentuk segitiga luar. Dalam urutan searah jarum jam mulai dari sudut atas, mereka membentuk angka-angka yang valid berikut: 39, 91, 13, 39, 91, dan 13. Pada segitiga dalam, berlawanan arah jarum jam dari sudut kiri atas, jumlahnya 13, 39, dan 91.

Kita dapat menggambar segitiga ketiga di dalam yang kedua yang merupakan salinan dari yang pertama, seperti yang ditunjukkan pada Gambar 2.c - dan yang keempat dan kelima dan seterusnya hingga tak terbatas. Segitiga terbalik dan turun $(\Delta \nabla \Delta \nabla \ldots)$ selamanya. Kita sebut dengan solusi 
siklus 1 karena dapat mengulangi segitiga yang sama selamanya. Solusi siklus 2, sebaliknya, membalik-balik antara dua segitiga yang berbeda.

Solusi siklus 4 , seperti yang diduga, menggunakan 4 segitiga berbeda. Bisakah Anda mencari tahu? Bisakah Anda menemukan siklus yang lebih tinggi?

Gambar 3 adalah solusi siklus 4 . Solusi siklus 4 ini dikenal sebagai solusi Ashbacher sesuai dengan nama penemunya, Charles Ashbacher . Belum diketahui siapa yang menemukan siklus yang lebih tinggi. Tetapi mengingat bahwa solusi ini hanya menggunakan kelipatan 7, mungkin ada siklus yang lebih tinggi menggunakan kelipatan 7 dan 13 .

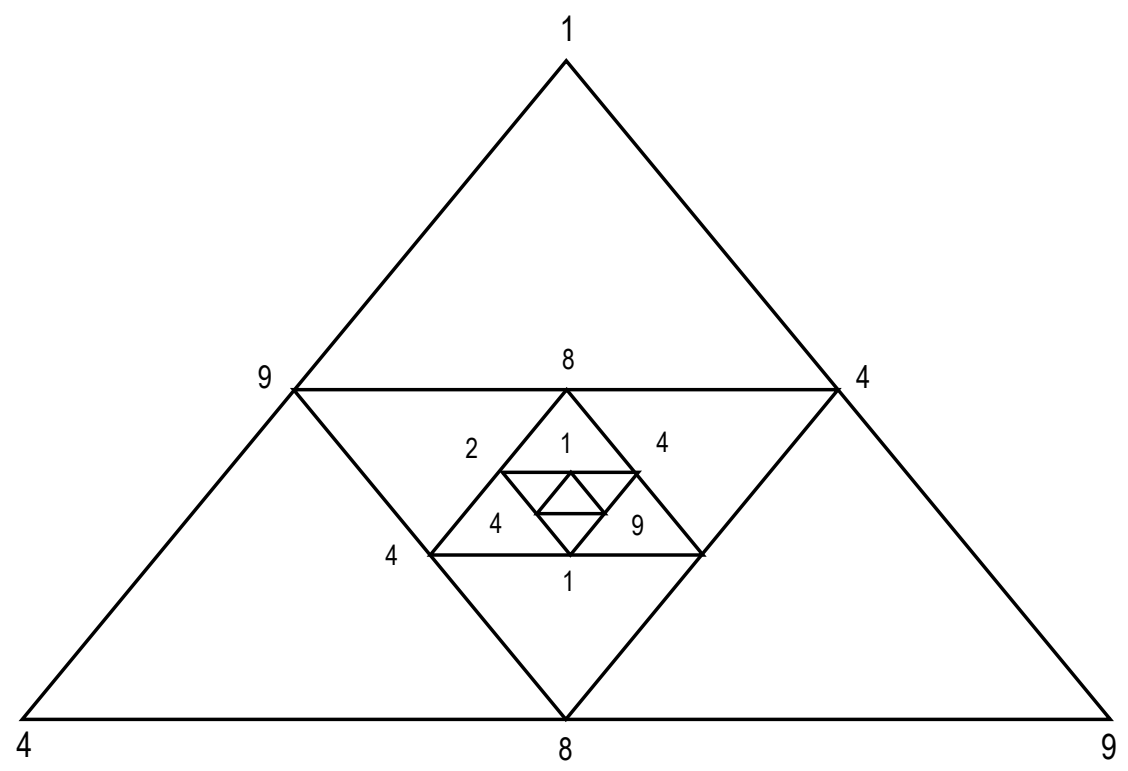

Gambar 3. Solusi Siklus Segitiga

Berikut adalah beberapa tantangan tambahan: Pilih angka acak antara 1 dan 9. Letakkan di sudut kiri bawah segitiga awal. Bisakah Anda membuat siklus 2? Apakah ada solusi untuk nomor awal yang Anda pilih? Apa solusi siklus terbesar yang dapat ditemukan?

\section{c. Seiring datangnya laba-laba}

Pada sebuah hutan hujan tropis tinggallah tiga ekor laba-laba yang bernama Pak Delapan, Pak Sembilan, dan Pak Sepuluh. Laba-laba tersebut dinamakan sesuai dengan jumlah kaki masing-masing yang dimiliki. Semuanya biasanya cukup senang dan menikmati keanekaragaman hewan dengan siapa mereka berbagi areal hutan. Namun hari ini, cuaca yang panas membuat mereka marah.

"Saya pikir ini menarik," kata Pak Sepuluh, "tidak seorang pun dari kita memiliki jumlah kaki yang sama dengan nama kita". 
"Siapa yang peduli?" membalas laba-laba dengan 9 kaki. Berapa banyak kaki yang dimiliki Pak Sembilan?. Hebatnya, adalah mungkin untuk menentukan jawabannya, meskipun sedikit informasi yang diberikan.

Sekarang untuk bagian kedua dari masalah. 3 laba-laba yang sama telah membangun 3 jaring. Satu jaring menangkap hanya lalat, yang lain hanya nyamuk, dan yang ketiga lalat dan nyamuk. Mereka memberi label pada 3 jaring mereka, masing-masing "lalat," "nyamuk," dan "lalat dan nyamuk." Sayangnya, semua label tidak ada yang benar. Serangga terbungkus rapat dalam untaian jaring. Berapa banyak serangga yang harus diambil laba-laba untuk melabeli jaring dengan benar?

Penyelesaian: Untuk masalah pertama, perhatikan bahwa Pak Sepuluh tidak dapat memiliki $10 \mathrm{kaki}$, jadi ia harus memiliki 8 atau 9 kaki. Karena laba-laba dengan 9 kaki menjawab komentar Pak Sepuluh, Pak Sepuluh tidak dapat memiliki 9 kaki. Oleh karena itu Pak Sepuluh memiliki 8 kaki. Sekarang pertimbangkan Pak Sembilan. Dia tidak dapat memiliki 9 kaki, karena ini akan cocok dengan namanya. Pak Sembilan memiliki 10 kaki.

Untuk masalah kedua, 1 serangga sudah cukup. Lepaskan 1 serangga dari jaring berlabel "lalat dan nyamuk". Katakan itu lalat. Karena setiap jaring diberi label secara tidak benar, jaring tersebut tidak dapat menjadi jaring "lalat dan nyamuk", dan oleh karena itu jaring tersebut harus merupakan jaring lalat. Jaring berlabel "nyamuk" harus mengandung serangga campuran, dan jaring berlabel "lalat" harus benar-benar jaring nyamuk.

Ini adalah masalah dengan 4 jaring berlabel "lalat dan nyamuk", "nyamuk dan semut", "semut dan tawon", dan "hanya tawon". Semua label salah. Berapa banyak serangga yang harus diambil untuk memberi label yang benar pada jaring, jawabannya adalah 3 .

\section{d. Kekeliruan matematis dalam geometri}

Gagasan tulisan berikut adalah untuk memberikan referensi ke sumbersumber kekeliruan matematis, karena ini dapat memberikan bobot yang lebih kepada para penggemar matematika.

Semua matematikawan terkadang dapat melakukan kekeliruan matematis. Kekeliruan matematis adalah suatu manipulasi proses yang dibawa kepada kesimpulan yang salah tetapi masuk akal.

Sekarang, lihat kekeliruan ketika kita akan membuktikan bahwa setiap segitiga adalah sama kaki, misalkan pada Gambar 4, untuk membuktikan bahwa segitiga PQR sama kaki maka harus dibuktikan bahwa $P Q=P R$.

Jika garis bagi internal sudut $\mathrm{P}$ bertemu $\mathrm{QR}$ pada $\mathrm{S}$, maka, dengan teorema sudut-garis (the angle-bisector theorem),

$$
\frac{S Q}{P Q}=\frac{S R}{P R} \text {. }
$$


sekarang $\angle P S Q=\angle P R S+\angle R P S=R+\frac{1}{2} P$

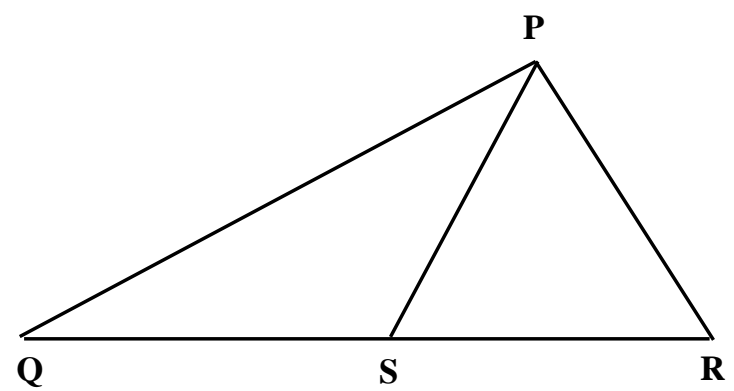

\section{Gambar 4. Segitiga PQR Sama Kaki}

terapkan aturan sinus pada segitiga PSQ, akan diperoleh,

$$
\frac{S Q}{P Q}=\frac{\sin Q P S}{\sin P S Q}=\frac{\sin \frac{1}{2} P}{\sin \left(R+\frac{1}{2} P\right)}
$$

selanjutnya,

$$
\angle P S R=\angle P Q S+\angle Q P S=Q+\frac{1}{2} P
$$

lalu,

$$
\frac{S R}{P R}=\frac{\sin \frac{1}{2} P}{\sin \left(Q+\frac{1}{2} P\right)}
$$

maka

$$
\frac{\sin \frac{1}{2} P}{\sin \left(R+\frac{1}{2} P\right)}=\frac{\sin \frac{1}{2} P}{\sin \left(Q+\frac{1}{2} P\right)}
$$

karena $\sin \frac{1}{2} P \neq 0$, maka $\angle P \neq 0$, oleh sebab itu $\sin \left(R+\frac{1}{2} P\right)=$ $\sin \left(Q+\frac{1}{2} P\right)$, atau $R+\frac{1}{2} P=Q+\frac{1}{2} P$, atau $R=Q$

Oleh karena itu segitiga sama kaki.

Analisis kesalahan ini dapat digunakan untuk menggambarkan fitur standar yang sering ditemui.

Untuk memulainya, tentu saja, kesalahan yang sebenarnya harus dideteksi. Langkah salah di sini adalah

$$
\sin \left(R+\frac{1}{2} P\right)=\sin \left(Q+\frac{1}{2} P\right)
$$

Kesetaraan sinus tidak harus berarti kesetaraan sudut.

Tahap kedua adalah untuk menghasilkan, seolah-olah, pernyataan rekonsiliasi di mana (i) deduksi yang benar diganti dengan yang salah dan, 
jika mungkin, (ii) perbedaan antara teorema yang salah dan yang benar dicatat secara penuh.

Berikut langkahnya

$$
\sin \left(R+\frac{1}{2} P\right)=\sin \left(Q+\frac{1}{2} P\right)
$$

tidak hanya mengarah pada kesimpulan yang dinyatakan oleh

$$
R+\frac{1}{2} P=Q+\frac{1}{2} P
$$

tetapi juga untuk alternatif

$$
R+\frac{1}{2} P=180^{0}-\left(Q+\frac{1}{2} P\right)
$$

atau

$$
P+Q+R=180^{\circ}
$$

Perlunya sudut $\mathrm{Q}, \mathrm{R}$ untuk menjadi sama dinegatifkan oleh fakta bahwa jumlah sudut $\mathrm{P}, \mathrm{Q}, \mathrm{R}$ selalu $180^{\circ}$. Karenanya kekeliruan didapatkan dan versi yang benar diganti.

Biasanya seseorang akan mulai dengan pernyataan dari argumen yang keliru, kemudian mengikutinya dengan paparan di mana kekeliruan ditelusuri ke sumber yang paling dasar. Akan ditemukan bahwa proses ini dapat mengarah pada analisis kedalaman yang tidak terduga, khususnya dalam kekeliruan geometris seperti pada contoh berikut.

Untuk membuktikan bahwa jika PQRS adalah sebuah segiempat di mana $P Q=R S$, maka PS harus sejajar dengan $Q R$.

Pada gambar 5, PQRS adalah segiempat di mana PQ = RS. Sekarang harus dibuktikan bahwa PS harus sejajar dengan QR.

Sekarang, gambarkan garis-garis tegak lurus dari PS, QR. Jika PS sejajar QR, teorema terbukti. Jika tidak sejajar, misalkan mereka bertemu di $\mathrm{O}$, yang mungkin di luar (Gambar 5a) atau di dalam (Gambar 5b) segi empat.

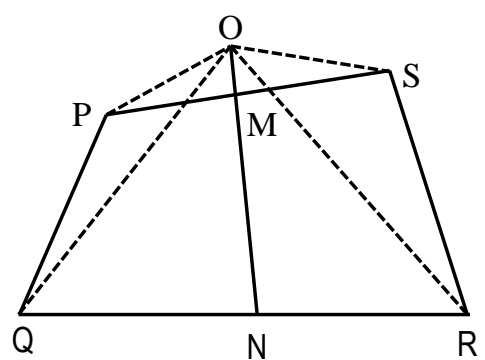

(a

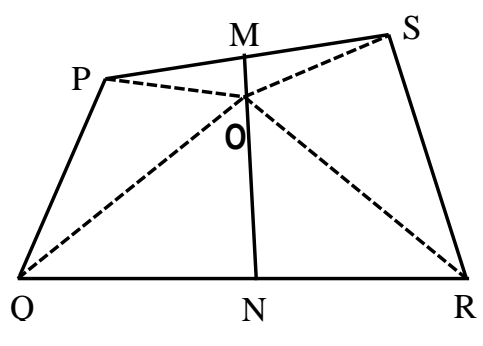

(b

Gambar 5. Garis Tegak Lurus pada Segiempat PQRS

Garis-bagi garis yang tegak lurus adalah lokus poin yang sama-sama jauh dari ujungnya. Karenanya 


$$
\begin{aligned}
& \mathrm{OP}=\mathrm{OS} \\
& \mathrm{OQ}=\mathrm{OR}
\end{aligned}
$$

Bandingkan segitiga OPQ, OSR.

$$
\begin{aligned}
& \mathrm{OP}=\mathrm{OS} \quad \text { (terbukti) } \\
& \mathrm{OQ}=\mathrm{OR} \quad \text { (terbukti) } \\
& \mathrm{PQ}=\mathrm{SR} \quad \text { (diberikan) } \\
& \therefore \quad \Delta \mathrm{OPQ} \equiv \Delta \mathrm{OSR} \\
& \therefore \quad \angle \mathrm{OPQ}=\angle \mathrm{OSR}
\end{aligned}
$$

Juga, dengan segitiga sama kaki,

$$
\therefore \quad \angle \mathrm{OPS}=\angle \mathrm{OSP} \quad(\mathrm{OP}=\mathrm{OS})
$$

Oleh karena itu, dengan substraksi (Gambar. 5a) atau addisi (Gambar. 5b),

$$
\therefore \quad \angle \mathrm{QPS}=\angle \mathrm{RSP}
$$

Demikian pula

$$
\begin{array}{lll} 
& \therefore \quad \angle \mathrm{OQP}=\angle \mathrm{ORS} & \\
\text { dan } & \angle \mathrm{OQR}=\angle \mathrm{ORQ} & (\mathrm{OPQ} \equiv \triangle \mathrm{OQSR})
\end{array}
$$

Oleh karena itu, dengan penambahan,

$$
\angle \mathrm{PQR}=\angle \mathrm{SRQ}
$$

Jadi

$$
\angle \mathrm{QPS}+\angle \mathrm{PQR}=\angle \mathrm{RSP}+\angle \mathrm{SRQ}
$$

Tetapi jumlah dari keempat sudut ini adalah empat sudut siku-siku, karenanya itu adalah sudut PQRS segiempat. Karena

$\angle \mathrm{QPS}+\angle \mathrm{PQR}=2$ sudut siku-siku,

Juga ini adalah sudut dalam untuk garis PS, QR dengan PQ transversal.

Jadi PS sejajar QR.

\section{e. Kekeliruan matematis dalam aljabar dan trigonometri}

Sekarang lihat kekeliruan matematis berdasarkan pengabaian aturan dasar dari manipulasi aljabar dan trigonometri.

Dari

$$
\begin{gathered}
\cos ^{2} x=1-\sin ^{2} x \\
\cos x=\left(1-\sin ^{2} x\right)^{\frac{1}{2}}
\end{gathered}
$$

Tambahkan 1 pada masing-masing suku, diperoleh

$$
1+\cos x=1+\left(1-\sin ^{2} x\right)^{\frac{1}{2}}
$$

Selanjutnya, kuadratkan masing-masing sisi

$$
(1+\cos x)^{2}=\left\{1+\left(1-\sin ^{2} x\right)^{\frac{1}{2}}\right\}^{2}
$$

Khususnya, jika $x=\pi$,

$$
\begin{aligned}
(1-1)^{2} & =\left\{1+(1-0)^{\frac{1}{2}}\right\}^{2} \\
0 & =(1+1)^{2}
\end{aligned}
$$




$$
\begin{aligned}
& 0=(2)^{2} \\
& 0=4
\end{aligned}
$$

Kekeliruan matematis terjadi didasarkan pada ambiguitas tanda yang muncul setiap kali akar kuadrat diambil.

Persamaan $x^{2}=a^{2}$, akan mempunyai dua penyelesaian yakni,

$$
x=+a, \quad x=-a
$$

\section{f. Kekeliruan pada bilangan yang sama}

Kekeliruan dalam memahami persoalan matematika selanjutnya dapat dilihat dalam operasi aljabar berikut:

$$
p=q+r
$$

dimana $p, q$, dan $r$ adalah bilangan positip. Lakukan operasi perkalian pada kedua sisi dengan $p-q$, untuk memperoleh,

$$
p^{2}-p q=p q+p r-q^{2}-q r
$$

Kurangkan kedua sisi dengan :

$$
p^{2}-p q-p r=p q+p r-q^{2}-q r-p r
$$

Sederhanakan persamaan:

$$
p^{2}-p q-p r=p q-q^{2}-q r
$$

Factorkan:

$$
p(p-q-r)=q(p-q-r)
$$

Bagi kedua sisi dengan $(p-q-r)$. Diperoleh

$$
p=q
$$

Untuk mendapatkan ilustrasi yang lebih konkrit, gunakan bilangan aktual sebagai berikut :

$$
3=2+1
$$

dimana $p=3, q=2$, dan $r=1$ adalah bilangan positip.

Selanjutnya kalikan kedua sisi dengan $3-2$, diperoleh,

$$
3(3-2)=(3-2)(2+1)
$$

Perluas persamaan ini untuk mendapatkan suku-suku yang multiplikatif:

$$
3.3-3.2=3.2+3.1-2.2-1.2
$$

Kurangkan ke dua sisi dengan $3 \times 1$ :

$$
3.3-3.2-3.1=3.2+3.1-2.2-1.2-3.1
$$

Sederhanakan persamaan :

$$
3.3-3.2-3.1=3.2-2.2-1.2
$$

Faktorkan :

$$
3(3-2-1)=2(3-2-1)
$$

Bagi ke dua sisi dengan $3-2-1$. Maka didapatkan

$$
3=2
$$

Hasilnya sangat kontradikstif, dimana secara nyata seharusnya 3 lebih besar dari 2, proses yang keliru akan mendapatkan hasil 3 sama dengan 2 . 


\section{KESIMPULAN}

Berdasarkan tulisan diatas, maka proses pembelajaran Matematika harus dilakukan dengan cara yang menyenangkan sehingga peserta didik tergugah semangatnya untuk dapat mempelajari Matematika lebih dalam lagi. Penggunaan simbol, gambar maupun tantangan berupa teka-teki ataupun permasalahan yang terjadi dalam kehidupan sehari-hari harus lebih sering ditampilkan. Peserta didik harus dapat diyakini bahwa ada harmoni di alam semesta yang dapat diekspresikan dengan bilangan bulat. Sebagai contoh, pola numerik yang dapat menggambarkan susunan kuntum bunga aster, reproduksi kelinci, orbit planet, harmoni musik, serta hubungan antara unsur-unsur dalam tabel periodik.

Bilangan bulat terdapat dalam semua aspek dalam Matematika, sama seperti kekeliruan matematis yang menyertainya. Diperlukan kesungguhan, ketelitian dan kehati-hatian dalam menyelesaikan setiap proses operasi matematika. Hubungan bilangan bulat dan kekeliruan matematis adalah untaian fundamental dalam menenun matematika. Seperti ungkapan seorang ahli Matematika Jerman Carl Friedrich Gauss, "Matematika adalah ratu ilmu dan teori bilangan adalah ratu matematika. Dan, jembatan diantara keduanya adalah kekeliruan matematis.

\section{DAFTAR PUSTAKA}

Pickover, C.A. (2001). Wonders of Numbers, Adventures in Mathematics, Mind, and Meaning, Oxford University Press.

Ryan D. Enos, Anthony Fowler, and Christopher S. Havasy. (2017). The Negative Effect Fallacy: A Case Study of Incorrect Statistical Reasoning by Federal Courts. Journal of Empirical Legal Studies, 14(3), 618-647.

Maxwell, E.A. (1963). Fallacies in mathematics, Cambridge at the university press.

Mary Mueller and Dina Yankelewitz. (2014). Fallacious argumentation in student reasoning: Are there benefits?. European Journal of Science and Mathematics Education, 2(1).

Anant Godbole, Zach Higgins, Zoe Koch. (2018). Finite Representability of Integres as 2-Sums. Integers 18B.

Francisco Vargas, Tommaso Benincasa, Giuseppe Cian, Laura Martignon. (2019).

Fostering Probabilistic Reasoning Away from Fallacies: Natural Information Formats and Interaction between School Levels. International Electronic Journal of Mathematics Education e-ISSN: 1306-3030. 2019, 14(2), 303-330. 
Yong Lu. (2016). The Conjunction and Disjunction Fallacies: Explanations of the Linda Problem by the Equate-to-Differentiate Model. Springerlink.com. Integr Psych Behav (2016) 50:507-531. DOI 10.1007/s12124-015-93146.

Maurice A.Finocchiaro. (2015). The fallacy of composition: Guiding concepts, historical cases, and research problems. Journal of Applied Logic 13, 24 43.

Rachel Croson and James Sundali. (2005). The Gambler's Fallacy and the Hot Hand: Empirical Data from Casinos. The Journal of Risk and Uncertainty, 30(3), 195-209.

James E. Ciecka \& Gary R. Skoog. (2018). Life Expectancies and Annuities: A Modern Look at an Old Fallacy. Journal Mathematics Magazine, 91(3), 163-170.

Mathematecian Leopold Kronecker. Retrieved from : http://mathshistory.st-andrews.ac.uk/Biographies/Kronecker.html

Trzeciak, J. (1995). Writing mathematical papers in english, a practical guide. European mathematical society, Germany.

Johann Carl Friedrich Gauss. Retrieved from: http://mathshistory.st-andrews.ac.uk/Biographies/Gauss.html

Edward N. Zalta. (1999). Natural Numbers and Natural Cardinals as Abstract Objects: A Partial Reconstructionof Frege's Grundgesetzein Object Theory. Journal of Philosophical Logic, 619-660.

Jun-Ling Sun and Chao-Ping Chen. (2016). Shafer-type inequalities for inverse trigonometric functions and Gauss lemniscate functions. Journal of Inequalities and Applications, DOI 10.1186/s13660-016-1157-2.

Georgios Spithourakis and Sebastian Riedel. (2018). Numeracy for Language Models: Evaluating and Improving their Ability to Predict Numbers. Proceedings of the $56^{\text {th }}$ Annual Meeting of the Association for Computational Linguistics, 1, 2104-2115.

Petr Girg and Lukáš Kotrla. (2016). p-Trigonometric and p-Hyperbolic Functions in Complex Domain. Abstract and Applied Analysis, 2016, Article ID 3249439, 18 pages. http://dx.doi.org/10.1155/2016/3249439. 